\title{
Understanding Key Concepts in Educational Research Through a Review of Two Research Articles
}

\author{
Ahmad Budairi \\ Ahmad Dahlan University, Yogyakarta \\ Ahmad.Budairi@monash.edu
}

\begin{abstract}
This paper is intended to help novice researchers understand key concepts in educational research, particularly in the field of language education. It uses as its samples two peer-reviewed research articles on early childhood literacy development, bilingual and multilingual issues and identity consitution. It first attempts to analyze how the key concepts in educational research were incorporated into the research process. Of particular importance, this paper critically looks at the extent to which those key concepts were logically linked so as to provide the research with strong coherence. The discussion also takes into account the issues of ethics, how this was sufficiently dealt with by the author and what possible factors might have come into play to degrade the validity of the research. This paper conludes with my views on the research design and process as a whole and my suggestions on some of the issues uncovered during the discussion.
\end{abstract}

\section{Introduction}

For many academicians, undertaking research can be such an intelectually challenging task. In order to produce a piece of quality research, one must have a strong grasp of research in terms of theoritical framework, research design and process, methodologies and tools. For novice researchers, this task could be even more daunting as they might have to grapple early with some key terms and concepts in research. It is also equally challenging to get one's foothold in the different ways key concepts in research have been interpreted and understood by research scholars, and this has invariably thrown some fuzziness on what and how research can be best approached.

Given those arguments, I ventured to present my review of two peerreviewed articles in educational research in the hope of adding clarity to our current understanding of research particularly in the areas of education. As a point of departure, I have selected two peer-reviewed research articles on early childhood literacy development, bilingual and

Understanding Key Concepts in Educational Research Through a Review of 11 Two Research Articles 
multi lingual issues and identity formation. I will set out with an examination of the research approach; how this might be reflected in the two research articles in terms of ontological and epistemological positioning, research paradigms, rationale and research questions. I will subsequently review the two articles respectively in terms of methodology and methods. The questions being addressed include to what extent the methodology and method underpinning the research has been appropriately selected to suit the paradigm and the epistemological framework, how the methodology chosen is linked to the methods, and what techniques and tools are used to generate data. Within the discussion on methodology and methods, the issues of validity and reliability will inevitably be raised as they are inherently embedded in the selection of methods and the techniques of data collection. In the last section, I will address ethical issues and power relations which might impinge on the research process.

The first article reviewed in this essay is a research article entitled 'Language Ideologies Mediating Literacy and Identity in Bilingual Contexts' by Carmen M. Martinez-Roldan and Guillermo Malave published in Journal of Early Childhood Literacy (2004). The research presents the complex relationships between literacy, language ideologies and issues of identity in early childhood literacy. The second research article is entitled 'Multilingual Language and Literacy Practices and Social Identities Sunni Madrasah in Mauritius by Ambarin Mooznah Auleear Owodally published in Reading Research Quarterly (2012). For convenience in the discussion, they are respectively referred to as Article 1 and Article 2 .

The final section of this essay presents my conclusion drawing upon the entire discussion of the two research articles, highlighting the evident relationship between the key aspects of the research as well as my standpoint on the research as a whole.

\section{Research Process}

When embarking on research, it is very important at the outset to be clear, up-front, and honest about our ontology and epistemology in our research (Boden, Kenway \& Epstein, 2005). Whereas ontology is concerned with the nature of the knower -how we see the world epistemology is about what counts as knowledge; how we make sense of the world. Our ontological and epistemological position are crucial to identifying what we want to research and what theoretical framework, or paradigm, is used (Grix, 2002, Mackenzie \& Knipe, 2006).

In light of such understanding of research concepts, the two articles selected here can then be reviewed. The first article focuses on the topic of early childhood literacy development and emergent ideas about Spanish 
language in the context of bilingual schooling and Hispanic -American families. The researcher claims that research into early childhood literacy and child identity development has tended to focus on the factors at micro levels (school and classroom). Whilst this notion of lack of holistic approach to the issue might have risen from the researcher's exploration of previous research, he conceded that research on early childhood must embrace multiple factors at the macro levels of socio analysis. Therefore, the researcher takes into account the sociocultural context of the borderlands in the south-western United States, highlighting the interplay of factors from different sources at the micro and macro social levels. For example, the data for the study was collected in the wake of an aggressive mass media campaign against bilingual education in Arizona and in the context of controversies over immigration.

To frame his research, Martinez-Roldan sets out by making reference to a conservative, reductionist approach to literacy development, where literacy instruction is defined simply as the transmission of skills, detached from cultural context and ideological struggles.(Moll, 1999 as cited in Martinez-Roldan \& Malave, 2004). Having disagreed with this view, he decides to align himself with the sociocultural approach which focuses on how school-age children learn and develop concepts in collaboration with other adults and peers in and out of schools. (Lee and Smagorinsky, 2000 as cited in Martinez-Roldan \& Malave, 2004). He utilizes Vygotsky's concept of mediation to examine how language ideologies enacted in parents' discourses help determine both their children's literacy development and their identity formation throughout the process of socialization in early childhood.

Article 1 bears much similarity to Article 2 in the sense that the latter is also concerned with looking at the issue of literacy development from a broader socio cultural context. Owodally seeks to illuminate the multilingual literacy practices in two Sunni Madrasah (Islamic Boarding Schools) in Mauritius, particularly in the use of Mauritian Creole which has long been rejected as a language of education and literacy in the Mauritius context. She admittedly distances her view from -in fact seeks to challenge - the western discourse on Islamic education and school which have been described as sites breeding Islamic fundamentalism, violence, and terrorism by cultivating practices of rote learning, incessant recitation and meaningless memorization. She also argues that the distinction made between institutionalized and vernacular language does not reflect the complex relationship arising from multi lingual language literacy practices observed in the two madrasah, highlighting the fluid identities which are constantly traded in such practices. 
Owodally draws upon the theory of poststructuralist theoretical perspective to frame her research. The poststructuralist perspective emphasizes that language, as a socially and culturally situated phenomenon, is a site for the construction, and negotiation of identities, which are themselves embedded within larger ideological structures and discursive practices. The relationship between language use and identities is thus viewed as dynamic and mutable, potentially leading to 'multiple discontinuities and hybridities at the interstices of linguistics and cultural contact' (Blackledge \& Pavlenko, 2001, as cited in Owodally, 2011)

Having examined both of the researcher's ontological and epistemological positions - researcher's belief and views on how the research on the area has been conducted and the preexisting body of knowledge about the subject matter, it is clear that both research articles fall under the constructivist paradigms. A constructivist paradigm believes that reality is subjective and can be different in various contexts. A person's reality is socially constructed as a result of their experiences and how these are influenced by cultures, politics and social interactions (Darlaston-Jones, 2007). In both research articles, the researcher goes beyond physical entity to tap further into human experience; how children develop bilingual and multi lingual literacies and identity formation within a broad sociocultural context. Martinez-Roldan is interested in exploring Steve's cognitive and psychological experience in the use of Spanish minority language whereas Owodally seeks to illuminate the identity formation embedded in the multilingual and multi literacy practices. The two researchers, thus, deal with the intangible, subjective world of the research participants. They rely on the participants' view of the situation being studied and they recognize the impact on the research of the researcher's personal background. (Mackenzie \& Knipe, 2006)

The research paradigms adopted by the two researchers provide a guide to formulate their research questions. Martinez-Roldan sets out with such questions as to what consequences a negative image of Spanish speakers would have on Steve's identity formation, where this negative perception of Spanish speakers come from, which factors may have influenced the patterns of language use of the child and whether Steve's parents share and support the school's goals. Whilst it was not immediately apparent what research questions were posed in Article 2, Owodally made it clear that her aim was to analyze the relationship among multilingual language practices in the teaching and learning process in the two Sunni Madrasah and the issue of identity formation imbedded in such practices.

As far as the research process is concerned, I personally think that in both research articles, there is a strong line of logical coherence which establishes a strong link between the ontological and epistemological

Understanding Key Concepts in Educational Research Through a Review of 14 Two Research Articles 
position of the researcher with the selected paradigms, all contributing to the solidity of this research. Similarly, the research questions being posed also fit within the epistemological framework and paradigms. However, it will be examined later in the discussion on validity, to what extent both researchers have responded well to the research questions. Part of these tasks is to go through the selection of appropriate methodologies and methods.

\section{Methodology and Methods}

The question of which methodology and methods woud be best suited to the research purposes is very closely connected to research paradigms. In both articles, the researcher's epistemological framework and paradigms have logically prompted them to opt for a qualitative methodology to investigate the research questions. Qualitative methodologies provide the means to seek a deeper understanding and to explore the nuances of experiences not available through quantification. By utilizing these methodologies, we are able to expand on the 'what' questions of the human existence asked by positivism to include the 'why' and 'how' asked by constructionism (Darlaston-Jones, 2007). With regard to the methods, research conducted within a social constructionist epistemology is more likely to involve a heavy reliance on the spoken words through conversation, interviews, narrative and similar (Gergen, 2001b; Padget, 2004, as cited in Darlaston-Jones, 2007).

In both quantitative and qualitative research, validity and reliability are the key aspects which contribute to the credibility of the study. Validity is concerned with the extent to which a particular instrument chosen truly measures what it purports to measure. In qualitative research, however, this view has taken new forms. In qualitative data, validity may be addressed through honesty, depth, richness, and scope of the data achieved, the participants approached, the extent of triangulation and the disinterestedness and objectivity of the researchers. (Winter 2000, as cited in Cohen, Manion \& Morrison, 2007). Reliability deals with the question of whether using the same tools or instrument in different contexts may produce the same results. This view, however, is very positivist driven because it requires a degree of control and manipulation of phenomena, whereas naturalistic studies acknowledges the uniqueness and idiosyncrasy of situations and therefore cannot be replicated (Cohen et al., 2007).

In Article 1, Martinez-Roldan employed a case study as his approach to investigating the research questions. According to O'Toole and Beckett (2000). Case Study is not explicitly considered as a methodology but rather a choice of what to be studied. The case study focuses on a sevenyear old student named Steven who received bilingual instruction in school. Martinez worked in collaboration with another researcher, 
Guillermo Malave. The data was collected in two different phases using purposive sampling technique. The first data set was collected over the school year 1998/1999 in a second-grade bilingual school classroom through classroom observations and by recording children's participation in small group literature discussion. The researcher used eleven literature discussion out of 75 for in-depth analysis of the nature of bilingual children's response to literature. According to Martinez-Roldan, of the 21 students participating in the study, the school classified eleven as Spanishdominant speakers and 10 as English dominant speakers. As a secondary data, Martinez-Roldan also conducted interviews with each child's mother for eight case studies. The other researcher, Malave, conducted a second study consisting of in-depth interviews with 20 families in two different socio cultural contexts, 10 in Arizona and 10 in Iowa in May 2000. It is very clear that Martinez-Roldan attempted to ensure the validity of the data through triangulation. Triangulation may be defined as the use of two or more methods of data collection in the study of some aspect of human behavior. Data or inferences that have been corroborated from at least two other independent angles are logically three times as likely to be true as uncorroborated data. (O'Toole \& Becket, 2010).

The triangulation used by Martinez-Roldan resulted in the different data sets which indeed corresponded to the issues encapsulated by the research questions. It is interesting, however, to see how the triangulation worked in this particular case study. As pointed out by Leedy and Ormon (2001, as cited in O'Toole \& Becket, 2010), case studies are useful for 'learning more about a little known or poorly understood situation' and where 'the phenomenon under study is not readily distinguishable from its context' (Yin, 2003, p.4 as cited in O'Toole \& Becket, 2010). Through triangulation, Martinez-Roldan was able to deal with the scope of his research questions, highlighting both the micro and macro sociocultural contexts through two levels of data analysis - school and family context- and to apply an inductive approach to analyzing the data in order to look for what is unique (O'Toole \& Becket, 2010). As admitted in the research article, having analyzed the data, MartinezRoldan decided to focus on Steve because he was the only student who, although of Mexican background, expressed negative perceptions about the Spanish language and Spanish speakers.

Martinez-Roldan used Critical Discourse Analysis as a method to study language as a discourse and language in its relation to society and ideology, in particular to identify propositions that represent participants' beliefs and attitudes concerning language and identity (Fairclough, 1989; van Dijk, 1998 as cited in Martinez-Roldan \& Malave, 2004 ). MartinezRoldan also related his analysis to what Fairclough termed as 'Critical language study' in which it seeks to show up connections that may be

Understanding Key Concepts in Educational Research Through a Review of 16 Two Research Articles 
hidden from people - such as connection between language, power and ideology (Fairclough, 1989 as cited in Martinez-Roldan \&Malave, 2004). Through CDA, he attempted to link a micro level of analysis of language with the macro level of analysis of social structure, power relations, and ideological struggles between groups.

From my point of view, the researcher's use of Critical Discourse Analysis is well suited to the purpose of his research. CDA allows him to Illuminate not only Steve 's bilingual literacy development at the level of linguistic features such as word meanings, vocabulary, propositions, but also how the dominant ideological discourse on bilingualism has impacted the way Steve's parents developed their discourse on the use of Spanish at home which in turn shaped Steve's beliefs and perception about Spanish language. Likewise, through the research findings, Martinez-Roldanhas convincingly presented the data to support the findings with a view to the researcher's limitation, epistemological framework, paradigm and data collection process. For example, through an analysis of the data from Steve's literary discussion class and mediation of texts it was revealed that Steve was developing a cultural model that considered Spanish speakers as not being smart and that Steve experienced tension in the family with regard to the use of Spanish. Similarly, through the story-telling of Steve's parents, the researcher was able to tap into the initially hidden fact that Steve's parents developed contradictory discourse on Spanish language, believing in the instrumental value of Spanish for getting a jobs but rejecting the teaching of Spanish in school. Martinez-Roldan also admitted the limitation of his findings by saying that there was nonetheless no evidence illustrating Steve's self-identification with an ethnic group. This particular self-reflection is very essential in qualitative research as it is often not possible to deal with an issue in its entirety and a researcher needs to be honest about it.

It can be concluded that this research has maintained its internal validity because it provides an explanation of particular issue which can be sustained by the data collected (Cohen, et al., 2007). In terms of generalizability, the claims made of this research may be best understood as dependent on the use of relevant literature and information collected in the study to support the arguments. (Freeman, deMarrais, Preissle, Roulsten \& Pierre, 2007). Here lies the question of research credibility. Credibility in qualitative study is concerned with data as standards of evidence to generate claims using the theoretical framework prescribed (Freeman et al., 2007). This notion is evident in the article in which there is a strong link between key aspects of the research, providing this research with a high degree of credibility. 
It might be worth questioning, however, as to how the data collected from the videotaping of the classroom activities was analyzed and used to support the claims made by the research. This was not explicitly addressed in the research findings whereas using a video camera is considered as the most effective way of capturing some kind of permanent record of the action and therefore can reveal new and negative data (O'Toole \& Becket, 2010). Similarly, it was not revealed in the article how the data from the interviews with the other families was analyzed and contributed to the findings. It might be that these issues were addressed somewhere else in the research report.

Article 2 is also a case study of multilingual language and literacy practices at two Sunni Madrasah (Islamic schools) in Mauritius. Unlike Article 1, Article 2 does not focus on a single child, but it takes as its sample the children learning at the two Madrasahs. The first set of data was collected in July 2008 at Madrasah 1 whereas the second set of data was collected at Madrasah 2 from January through April 2010. Owodally used different methods of data collection such as semi-structured interviews, unstructured interviews, class observation and collection of artifacts. The data collected focused on various aspects such as language policy, language and literacy practices, production of textbooks and language choice for the textbooks, structure and language policy of the madrasah, language used in the presentation of the program and in the various performances.

With regard to the method of analysis, Owodally commented that being aware of her status as a Muslim woman immersed in the literacy, cultural and religious practices of the Sunni community under observation, she chose to adopt interpretive analysis as her main approach to data analysis. Interpretive analysis is described as ' making sense of social situation by generating explanations for what's going on within them...making inferences, developing insights, attaching significance, refining understandings, drawing conclusions and extrapolating lessons " (Hatch, 2000, as cited in Owodally, 2011) Based on this approach, Owodally looked for links between the different data sets, and the main themes across these data sets were then read against the data obtained from the interviews with the informants. By doing this triangulation, the informants were also given voice and their interpretations were considered in the data analysis.

Owodally's technique of data analysis has enabled her to address the research questions in a comprehensive manner. The findings have shown a whole range of issues which she initially intended to explore in her research. It was revealed that the Madrasah uses multi language literacy practices in the teaching and learning process and that there was a constant negotiation of identities traded across the use of different 
languages, proving that identities were so fluid in the context of the two Madrasah. These claims were well-sustained by the data generated. Thus, validity of this research was confirmed through the design of the research process, the methods of data collection and the tools for analysis.

However, as these two research articles are case studies, it is impossible to generalize from its findings (O'Toole \& Beckett, 2010). Nonetheless, both research findings have educative authenticity (Cohen et al., 2007) which suggests that the findings may generate a new appreciation of the issues and that within such notion the findings may be transferable to other situations and contexts.

\section{Ethical Issues}

In research, the issue of power and ethics may arise at any stage during data collecting process which, if not seriously addressed, may lessen the validity of research findings. As a matter of fact, research process is not a neutral act. The issue of power, for example, may arise during an interview between researchers and research subjects (Cohen \& Morison ). The nature of relationship between researchers and subjects being researched is often asymmetrical in terms of power because researchers have the power to interrogate the lived experience of the subjects being researched (O'Toole \& Beckett, 2010). Looking back at Article1, the data collecting process during classroom discussion may be worth questioning. First, the researcher's direct questions to Steve during classroom literary discussion may have injected asymmetrical power relation, with Steve feeling somewhat intimidated. Furthermore, it was not clear in the article how the researcher positioned and distanced himself with the students and to what extent he had established rapport with Steve and other students. Would Steve and other students have responded in the same way if their very own teacher, had asked the same questions? This may be worth considering particularly if measured against the fact that Steve was the only student who showed negative ideas about Spanish language in a classroom discussion attended by 21 participants. Similarly, the classroom discussion may have also been disrupted by the recording, regardless of the fact that the recording was being done by his coresearcher (O'Toole \& Beckett, 2010 ). This fact may have changed the nature of the research site and the data. Lastly, the researcher's personal bias also needs scrutinizing. Assuming that Martinez-Roldan ( judging from his name) was also a Latino-American, it is suspected that he may have developed a certain ideological discourse on Spanish whatever it be. In the context of political and mass media campaign against the teaching of Spanish, the research may have been designed with a preconceived agenda either in support or against the movement. 
The issue of ethics was central in the research article 2. Owodally's choice of paradigms, research sampling, methods of data collection and data analysis all have made the nature her interaction with research subjects, gatekeepers and informants so intensive that it was susceptible to the issues of ethics. Owodally, however, seems to have addressed this issue very well at different stages during the data collection process. For example, she situated herself as being a member of the local Muslim community by wearing the traditional Indian salwar and dupatta, an act which can be interpreted as paying respect to the rights of the subjects being researched. Owodally also informed the administrators at both Madrasah about her status as an academic interested in language and literacy. All of these have enabled her to obtain consent from the key persons in the two Madrasah. At some stages of data collection, she used snowballing technique in which one informant led her to another source of data, suggesting trust between the researcher and the research participants. It was not mentioned, however, if a letter of consent from the Head of Madrasah was sought or even considered necessary by the researcher. In qualitative research involving minor, ethical clearance is needed no matter how 'non-risky' it might seem ( O'Toole \& Beckett 2010). Nor it was explained to what extent the students were informed about the researcher and what they were expected to. If these issues had not been addressed in the research, the validity of this research would have somewhat decreased.

\section{Conclusion}

Research always entails a systematic and rigorous ways of investigating phenomena. Through the discussion, the two articles chosen for this essay have demonstrated, to a greater extent, how qualitative research works and what constitutes a good research. In both research articles, the key aspects in educational research have been appropriately addressed. The researcher's ontology and epistemology were strongly linked to the research questions. Likewise the methodology and methods were well chosen to suit the research paradigms. The extent of data triangulation was also suited to the need to respond to the research questions, resulting in the comprehensive data sets which were used to sustain the claims made. Through the research findings, both articles have demonstrated a detailed and comprehensive description of the issues being raised and responded accordingly to the research questions. There are, however, issues of power and ethics evident in both research articles which need to be taken into account because they might jeopardize the validity of the research to some extent.

As the two articles constitute case studies, it may be hard to generalize from its findings across different situations and contexts. However, as have been discussed, this does not necessarily mean that both research articles lack validity. In qualitative research, the notion of validity has 
shifted away from what is traditionally held by positivist. Validity can be understood and viewed from various aspects and standpoints. It may be achieved through richness and scope of the data, and the extent of triangulation as well as the description of design and method of the research. It is within this notion that the two research articles can be understood in terms of validity.

\section{References}

Boden, R., Kenway, J. and Epstein, D. (2005). 'The research process.' Getting started on research, London, Thousand Oaks; 36-49

Cohen, L; Manion, L and Morrison K. (2007). 'Validity and Reliablity'. Research Methods in Education. London: Routledge. 133-164.

Darlaston-Jones, D. (2007). 'Making connections: The relationship between epistemology and research methods.' The Australian Community Psychologist 19(1): 19-26

Freeman, M., deMarrais, K., Preissle, L., Roulston, K., \& Pierre, E. A. (2007). 'Standards of evidence in qualitative research: An incitement to discourse.' Educational Researcher, 36(1), 25-32.

Grix, J. (2002). Introducing students to the generic terminology of social research. Politics 22(3): 175-186.

Mackenzie, N. \& Knipe, S. (2006). 'Research dilemmas: Paradigms, methods and methodology,' Issues in Educational Research, 16 (2): 193-205.

Martinez-Roldan, C. M., Maleve, G. (2004) 'Language ideologies mediating literacy and identity in bilingual contexts.' Journal of Early Childhood Literacy 2004; 4: 155

O'Toole, J. and Beckett D., Eds. (2010). Educational Research: Creative Thinking and Doing. Oxford: Melbourne, Australia

Owodally, A. M. A. (2011). 'Multilingual language and literacy practices and social identities in sunni madrasahs in mauritius: a case study.' Reading Research Quarterly 2011; 134:155 